\title{
SRI Value Network Analysis
}

\author{
Slim Turki \\ Luxembourg-Kirchberg, Luxembourg
}

\begin{abstract}
Sustainable and responsible investments (SRI) are the type of investment which aims to achieve financial returns while performing in terms of extra-financial aspects, such as social, environmental, governance, and ethical objectives. This article is an attempt to deepen the analysis of the SRI value network; It aims to contribute to achieving better understanding of the specificity of SRI fund industry and involved stakeholders. It presents the current results of the analysis of the value network underlying SRI. It relies on the academic and professional literature to identify the involved stakeholders, their inter-dependencies and the exchanged values. The approach is based on combining goal and value analysis to identify the stakeholders, understand their motivations and reference the direct or indirect value exchanges that they could have.
\end{abstract}

Keywords: SRI, sustainable and responsible investment, finance, value network, goal analysis.

\section{Introduction}

Sustainable and responsible investments (SRI) could be defined as the type of investment which aims to achieve financial returns while performing in terms of extrafinancial aspects, such as social, environmental, governance, and ethical objectives (Vermeulen \& Mention, 2011.a). Eurosif's 2010 European SRI Study (Eurosif, 2010) estimates that the global SRI market has grown by more than $200 \%$ between 2006 and 2010 to reach $\$ 11$ trillion, and that the European SRI market share (AuM ${ }^{\mathrm{i}}$ ) has grown from $35 \%$ in 2006 to $71 \%$ in 2010 to reach $€ 5$ trillion. The SRI market is still expected to grow in the coming years.

This paper aims to contribute to achieving better understanding of the specificity of SRI fund industry and involved stakeholders. It presents the current results of the analysis of the value network underlying the sustainable and responsible investments (SRI). It relies on the academic and professional literature to identify the involved stakeholders, their interdependencies and the exchanged values.
The conceptual framework is presented in section 2. In section 3 , the identified stakeholders are introduced. In section 4 and 5, goal and value models are respectively presented and analysed. The prospects of this on-going work are discussed in the conclusion.

\section{Conceptual Framework}

As explained in (Allee \& Schwabe, 2011), while a value chain traditionally relates to a single chain of activities and usually applies to one firm operating in a specific industry, a value network is a "business analysis perspective that describes social and technical resources within and between businesses. The nodes in a value network represent people (or roles). The nodes are connected by interactions that represent tangible and intangible value objects. These objects take the form of knowledge or other intangibles and/or financial value. Value networks exhibit interdependence. They account for the overall worth of products and services".

Copyright (C) 2012 Slim Turki. This is an open access article distributed under the Creative Commons Attribution License unported 3.0, which permits unrestricted use, distribution, and reproduction in any medium, provided that original work is properly cited. Contact author: Slim Turki E-mail: slim.turki@tudor.lu 
To draw the SRI value network, two modelling techniques are combined:

1- Goal analysis: it aims to determine what various actors want and how (and whether) those wants will be achieved. The $i^{*}$ language is used (see Annexe 1: Goal Modelling Constructs). It stands for distributed intentionality, and builds on the premise that actors don't merely interact with each other through actions or information flows but relate to each other at an intentional level.

2- Value analysis: it allows representing a network of actors creating, distributing, and consuming things of economic value (see

3- Annexe 2: Value Modelling Constructs).

Indeed, the combination of these methods (Gordijn \& al., 2006) has proven its effectiveness in analyzing several business sectors (Turki \& al., 2008), (Turki \& Bjeković, 2009).

The value network analysis starts in the next section with the stakeholders identification.

\section{Stakeholders Identification}

One objective of this study is to identify the key actors involved in the SRI investment process. In practice, sustainable and responsible investment has most prominently taken the form of screened mutual funds, which assess and invest in large-capital companies (O'Rourke, 2003). Therefore, funds are considered the primary vehicle for realizing sustainable and responsible investments.

From professional and academic literature ((EFEMA, 2010), (Wilsdon \& Malcom, 2006), (Alexander, 1997), (Bollen, 2007), etc.), a set of roles, involved in the investment process, has been identified. Although a significant number of actors are involved, not all are interesting for our study. The choice was made to limit the focus on the actors or stakeholders that influence investment decisions, either by the choices they make, either by the services and / or information they provide, or actors who are influenced or impacted by these decisions or information.

For that reason, we make the choice to not consider in the SRI value network roles that only provide administrative services in the investment process; such as "Custodian bank", "Transfer agent", "Fund administrator", etc. Thus, a fund is considered as investment vehicle having an investment strategy, with a "sell side" in charge of the distribution of the fund shares, and a "buy side" in charge of the asset management.

In the following, our study will focus on the following roles:

1. Investor, whether individual or institutional

2. Investment vehicle, and mainly on the asset management and distribution activities

3. Investee

4. Regulator

5. Extra-financial rating agency

6. SRI labeller

7. SRI promoter

\section{Investor}

Generally speaking, investors, whether individual or institutional, put their money into some investment vehicle with goals of getting return from the invested capital. Investors seek to minimize the risks and maximize the returns. Subscribing to an investment vehicle is one of the means to minimize transaction costs. The investor investment choice is partially based on the information provided in the prospectus of the fund, which has to be validated by the regulation authority.

An investor, sensitive to responsibility and sustainability, would seek investment opportunities integrating extra-financial aspects, along with reaching satisfactory financial performance. 
(Renneboog \& al., 2008)reminds that if investors derive non-financial utility from investing in SRI funds or in companies meeting high standards of corporate social responsibility (CSR), then they care less about financial performance than 'conventional' (non-SRI) investors. (Bollen, 2007) ${ }^{\mathrm{ii}}$ argues that investors may have a multi-attribute utility function that is not only based on the standard risk-reward optimization but also incorporates a set of personal and societal values. In general, SRI investors expect companies to focus on social welfare in addition to value maximization.

\section{Investment Vehicle}

As explained previously, for the purpose of simplicity, the roles of the fund promoter, asset manager (investment manager) ("Buy side") and distributor ("Sell side") are grouped into a generic role "investment vehicle". This is to underline that main objectives of this role consist in attracting investments and generating a return on invested capital.

\section{○ Asset Management ("Buy side”)}

Socially responsible investing (SRI) is an investment process that considers the social and environmental consequences of investments, both positive and negative, within the context of rigorous financial analysis. It is a process of identifying and investing in companies that meet certain baseline standards or criteria of Corporate Social Responsibility (CSR) and is increasingly practiced internationally " (Eurosif, 2010). CSR has important implications for SRI, as SRI asset managers have to pursue both financial goals and social objectives.

The process of selecting an investment can be described as a series of screens being applied to define an investment universe and finally the investment itself; SRI funds work with the same method except that additional screens are also applied on the basis of additional criteria (which can be environmental, social, ethical, etc.)
(O’Rourke, 2003). Also, (O'Rourke, 2003) identifies and categorizes common research tools used by SRI fund analysts: (i) Primary research: questionnaires, site visits, discussions, telephone interviews, data checks; (ii) Company sources: corporate reports (financial, environmental and increasingly social), Policies, Press releases, Mandatory information (such as a toxic inventory list), Strategies and action plans, EMS documentation/certification; and (iii) $3^{\text {rd }}$ party sources: Non-government organisations, Data from regulatory agencies, Media, Industry organisations, Commercial ratings/assessments, Independent, non-profit rating schemas, Other "ethical" funds, Local communities.

\section{○ Distributor ("Sell side")}

The distributor is in charge of the marketing of the fund's shares/units. His action could be (i) Passive: It is required to receive and deal with the subscription / redemption orders; or (ii) Active: It is required to promote and market the fund's shares/units (Ferguson \& al., 2010).

\section{Investee}

Investee is the business entity in which an investment is made.

(Renneboog \& al., 2008) reminds that companies' only responsibility is a financial one so companies should maximize the value of their shareholders' equity. However, in recent years, Corporate Social Responsibility (CSR) has become a focal point of policy makers (and the public), who demand that corporations assume responsibility towards society, the environment, or the stakeholders in general.

CSR means open and transparent business practices that are based on ethical values and respect for employees, communities, and the environment. It is designed to deliver sustainable value to society at large, as well as to shareholders" (quoted in (Eurosif, 2010)). 


\section{Regulator}

Regulators are the official bodies iii in charge of the regulation and supervision of the financial market. The objectives of financial regulators, at national or regional, are generally:

- To maintain orderly financial markets and confidence in the financial system;

- To safeguard investments in financial instruments and in all other savings and investment vehicles;

- To bring about an orderly expansion of activities of the financial sector.

Among their tasks, we find:

- Regulate the financial markets and provide assistance to consumers of financial products and servicesiv;

- Oversee the enforcement of laws in each of the areas it regulates;

- Provide assistance to consumers of financial products and services;

- Ensure that the financial institutions and other regulated entities of the financial sector comply with the obligations imposed on them by law;

- Supervise the activities connected with the distribution of financial products and services;

- Oversee and monitor information to ensure that it is accurate, precise, fair and timely and that it is disseminated to the financial community as a whole (AMF);

- Authorise the creation of open-end and closed-end funds;

- Conduct inspections and investigations.

According to (Renneboog \& al., 2008), the growth of the SRI industry can be partly attributed to the changes in regulation regarding the disclosure of social, environmental and ethical information by pension funds and listed companies. Most of the regulatory SRI initiatives are taken by national governments, mainly in Europev,vi, vii, viii.

\section{Extra-Financial Rating and Labelling Agencies}

With the growth of SRI, a plethora of associated financial products, such as ratings tools and sustainability indexes have been launched in the past decade (O’Rourke, 2003).

There are two main categories of evaluation models:

\section{Extra-Financial Ratters}

Extra-financial ratters assess companies and provide the asset manager with investment universe including assets complying with CSR principles (according to their internal criteria). In this category, Vigeo ${ }^{\text {ix }}$ and Ethibel ${ }^{x}$ provide recognized evaluation models (Vermeulen \& Mention, 2011.c).

\section{$\underline{\text { SRI Labeller }}$}

One SRI Labelling agency is an organisation that awards labels to investment vehicles after the assessment of its extra-financial performance.

In Europe, the Novethic ${ }^{x i}$ SRI Label is a reference. It "aims to provide individual investors with a framework for Socially Responsible Investment (SRI) products offered by investment managers". The Label is awarded by Novethic's SRI Research Centre, to open-end funds whose management "systematically takes into account Environmental, Social and Governance criteria". In order to obtain the Label, the fund manager must detail the fund's SRI management approach, provide reporting on the extra-financial characteristics of the fund and disclose a complete list of portfolio holdings.

\section{SRI Promoters}

SRI promoters are the not-for-profit organizations whose aim is to stimulate, promote and support all types of SRI. 
In Europe, Eurosifxii and national SIFsxiii (Social / Sustainable Investment Forums) are playing this role and assume the mission to "develop sustainability through European financial markets". For example, BELSIFxiv, the "Belgian Sustainable and Socially Responsible Investment Forum" considers its main goal to be the promotion of knowledge about SRI in Belgium through the organization of lectures, research and publications. It provides the investors with an analytical tool (The Belsif matrix) helping them to make an informed investment by considering SRI elements.

\section{Goal Analysis}

Figure 1 shows the Strategic Rationale (SR) model of SRI stakeholders. This model shows that:

- The investment vehicle is dependant from investors' capital. In parallel, the investor is dependant from the vehicle to reduce its transaction costs.

- The investment vehicle is dependent from information supplied to it by the extra-financial rating agencies and the investees.

- To be authorized to practice, the investment vehicle has to comply with appropriate regulation, issued by the regulator- the official body in charge of the supervision of the financial market.

- The regulator bases its decisions on whether to permit the activities of investment vehicles and investees on the compulsory information that they have to publish.
- Investment vehicle targets SRI investor profile by adopting an SRI strategy integrating environmental, social \& governance concerns into its investment process. In addition, an SR Investment vehicle would perform activities promoting the SRI orientation of the vehicle.

- Obtaining an SRI label could help the investment vehicle to attract investors interested in SRI. A label is generally obtained after the filing of a request and payment of administrative expenses.

- SRI Labels and extra-financial rating agencies remain economic entities working to develop and preserve their market reputation. These entities also need to ensure their financial sustainability, and are therefore dependent on their customers (investment vehicles) or on other funding bodies.

- The investee would need to attract investments, and would perform financial reporting required by the regulator.

- Investees willing to attract the SRI funding could communicate on its corporate social responsibility, thus proving his interest in e.g. social, environmental and other aspects relative to SRI. The corresponding investee's reports are reviewed by extra-financial rating agencies, providing appreciation of investee extra-financial performance. The asset selection process of the SR Investment vehicle usually relies on these evaluations.

- SRI promoters aim at promoting socially and environmentally sound investing behaviour. 


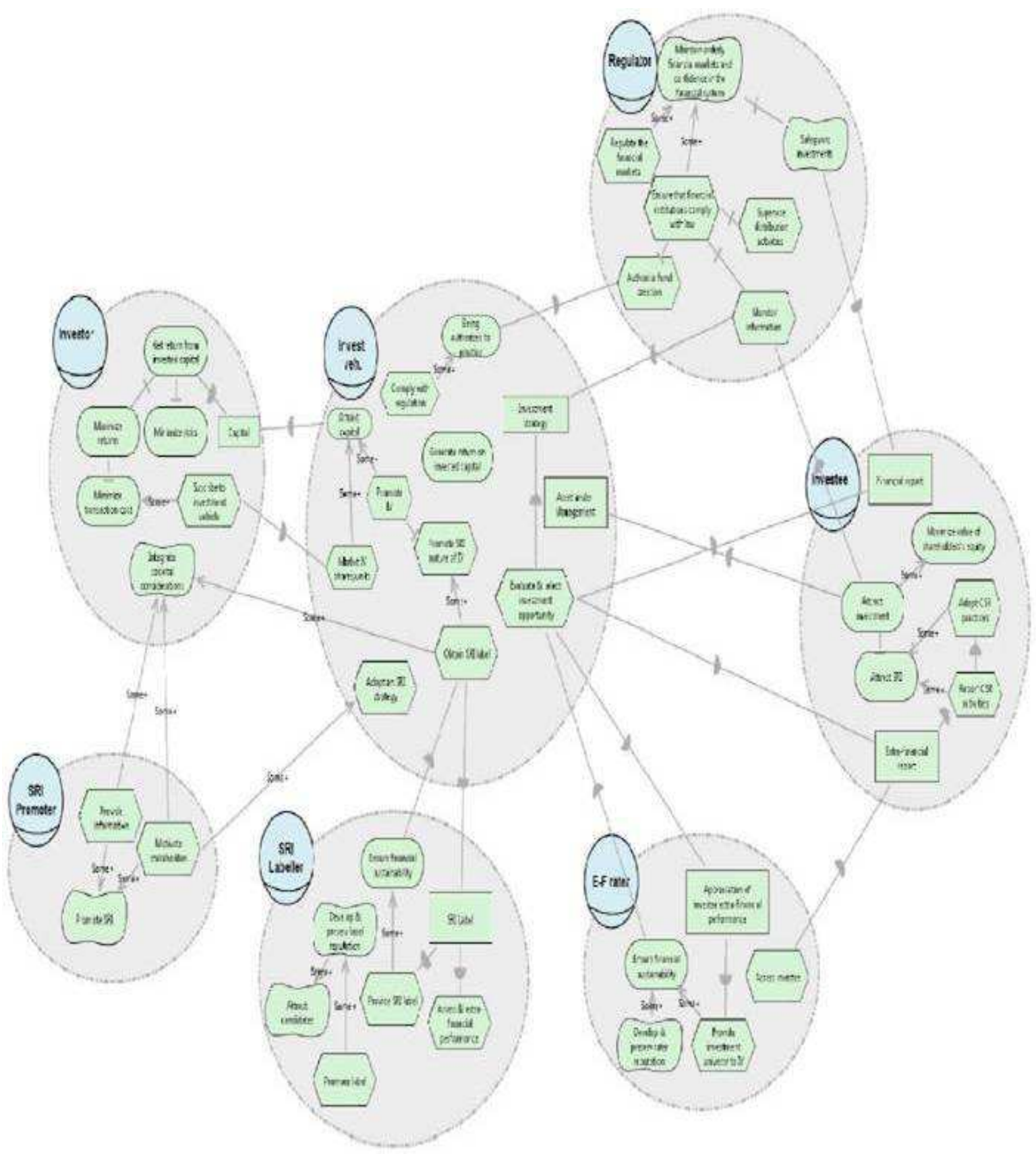

Figure 1: Goal Analysis - Strategic Rationale (SR) Model 


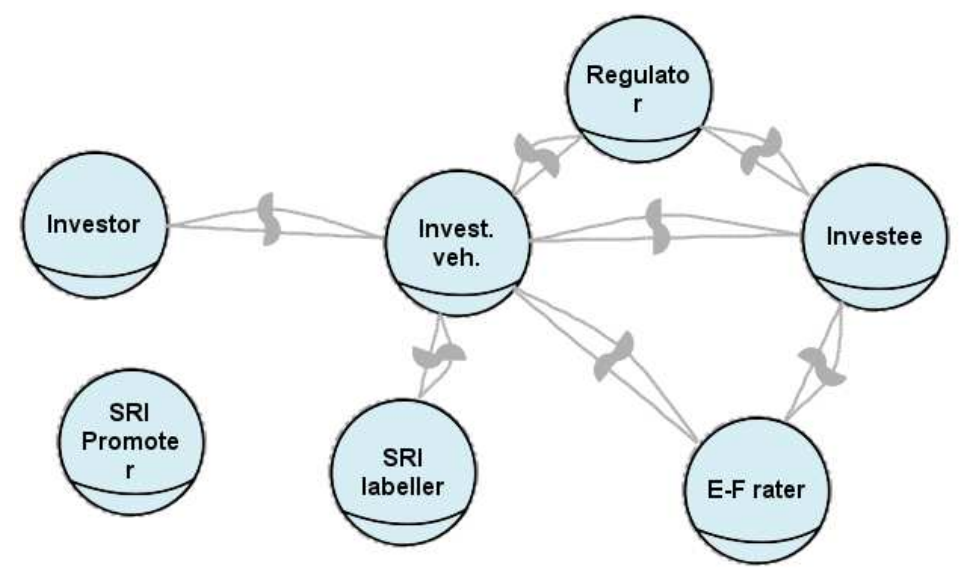

Figure 2: Goal Analysis - Strategic Dependency (SD) Model

Figure 2 shows the Strategic Dependency model of SRI. This graph shows the dependencies between actors. It also highlights the particular role of SRI promoter that appears not to be dependent on any other players even if having interactions with them.

\section{Sri Value Network}

The SRI Value Network represents the direct and indirect value exchanges between the involved stakeholders.

Figure 3 shows the current state of the model. The model represents in particular:

- The traditional exchanges of capital and dividends between the investor, the investment vehicle and the investee;

- The exchange of information and fees in return between the extra-financial ratter and the investment vehicle;
- The media exposure for the investment vehicle and that accompanies the label.

The model also shows other indirect exchanges of values:

- The awarding of a SRI label to an investment vehicle offers a form of exposure that may distinguish it from other vehicles to investors. The label can also be perceived by investors as a form of guarantee of the seriousness of the SRI strategy of the vehicle;

- An extra-financial rating agency, via its recommendations that it delivers to investment vehicles, acts indirectly, positively or negatively on the value and attractiveness of the investee;

- The regulator, allowing the vehicles and objects to practice investment, provides guarantees to the investor for the protection of his investment. 


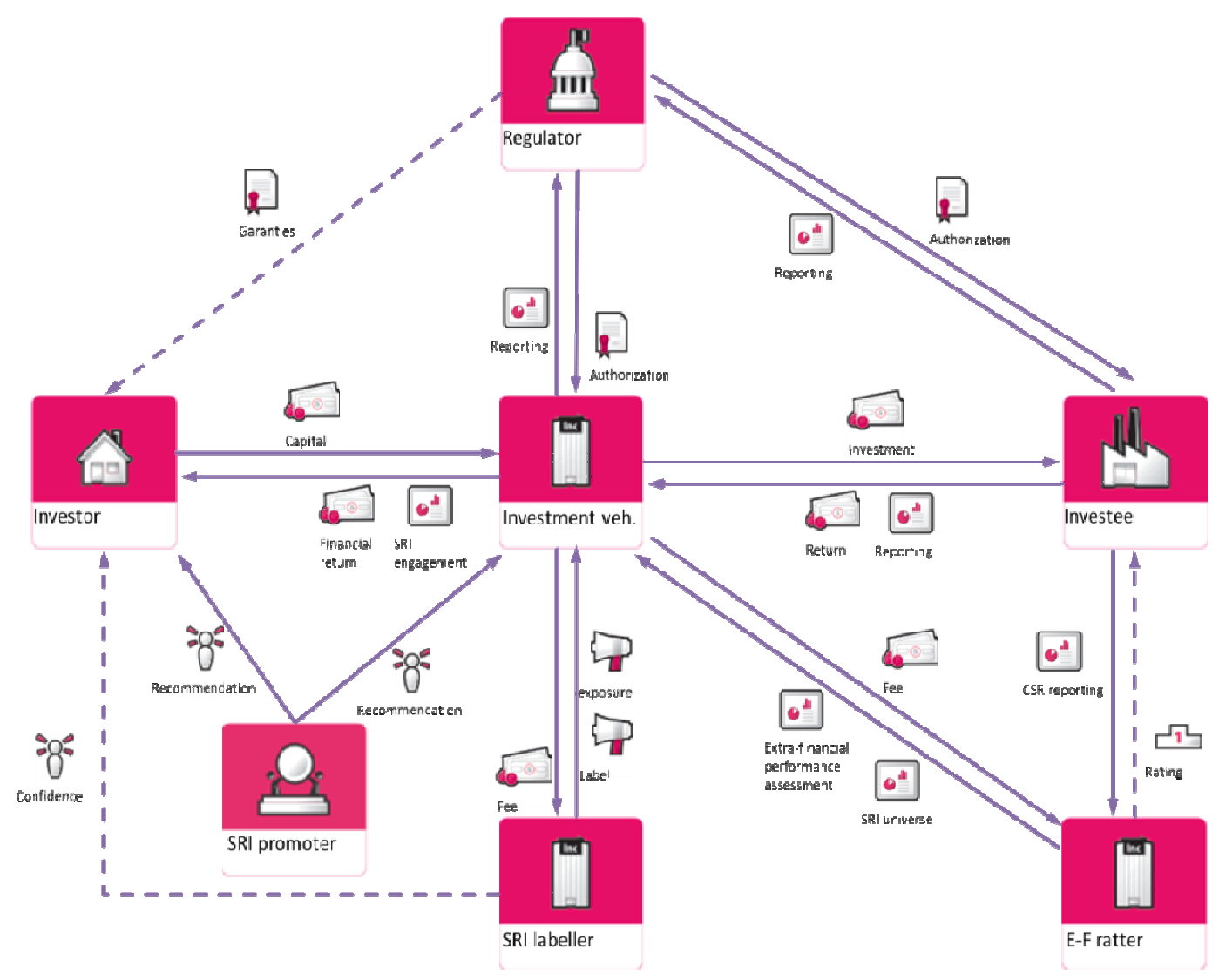

Figure 3: SRI Value Network

\section{Conclusion and Perspectives}

This article is an attempt to deepen the analysis of the SRI value network. The approach is based on combining goal and value analysis to identify the stakeholders, understand their motivations and reference the direct or indirect value exchanges that they could have.

The results of this on-going study are intended to serve the fund industry regulators, practitioners and researchers in SRI. The proposed models would serve as formalized tools to analyse the interactions between SRI market players; to detect possible conflicts of interest between the actors involved; to analyse overlaps or gaps with compliance matters; and other issues susceptible to have an impact on the value network.

The next stage of this work will focus on the validation of current models through interviews with a representative sample of stakeholders identified at the European level.

\section{Acknowledgment}

The presented work is lead in the frame of the project EMISSAIRE (Évaluation multidimensionnelle de l'investissement socialement responsable - Multidimensional evaluation of socially responsible investment) and is partially funded by the FEDER (Fonds Européen de Développement Régional) program.

\section{References}

Alexander, S. (1997). "Pension Funds and Economically Targeted Investments: Alternative Investment Resource for Inner City Revitalization," PhD Thesis, Chicago: University of Illinois, 1997.

Allee, V. \& Schwabe, O. (2011). Value Networks and the True Nature of Collaboration, Published by ValueNet Works and Verna Allee Ass.- ISBN\# 978-615- 
43765-1,

http://www.valuenetworksandcollaborati on.com/

Bollen, N. P. B. (2007). "Mutual Fund Attributes and Investor Behavior," Journal of Financial and Quantitative Analysis 42, p.683-708.

EFAMA (2010). "Asset Management in Europe: Facts and Figures," EFAMA's Third Annual Review, pp.37, 2010.

Eurosif European SRI Study 2010.

Ferguson, M. et al., (2010). "Investment Funds in Luxembourg: A Technical Guide," Ernst \& Young, pp.246, 2010.

Gordijn, J., Yu, E. \& van der Raadt, B. (2006). "e-Service Design Using i* and e3value Modeling," In IEEE Software, Vol. 23(3):2633, May 2006.

Juravle, C. \& Lewis, A. (2008). "Identifying Impediments to SRI in Europe: A Review of the Practitioner and Academic Literature," Business Ethics: A European Review, Vol. 17, No. 3, pp. 285-310, July 2008.

O'Rourke, A. (2003). "The Message and Methods of Ethical Investment," Journal of Cleaner Production, Volume 11, Issue 6, September 2003, Pages 683-693, ISSN 0959-6526.

Renneboog, L., Ter Horst, J. \& Zhang, C. H. (2008). "Socially Responsible Investments: Institutional Aspects, Performance, and Investor Behavior," Journal of Banking \& Finance, Volume 32, Issue 9, Sep 2008, Pages 1723-1742, ISSN 0378-4266.

Turki, S. \& Bjeković, M. (2009). Exploring Itinerancy Services: Itinerant User Goal Analysis. In proc. 4th inter. scientific conference. Rhodes, April 2009.

Turki, S., Bjeković, M. \& Vermeulen, C. (2011). Exploring Sustainable And Responsible Investment: Stakeholders' Value Exchange. In Proc. Of IBIMA'17, Milan, November 2011.
Turki, S., Kohlbecker, J., Grégoire, B. \& Latour, T. H. (2008). 'De l'intention a la Valeur dans un Dispositif de Formation pour Demandeurs d'emploi,' IBIMA'09, Marrakech, January 2008.

Vermeulen, C. \& Mention, A.- L. (2011.a). "Sustainable Financing: Collaborative Innovation Restoring Confidence in Regulated Environments," In Proc. of the ISPIM Conference, Hamburg, June 2011.

Vermeulen, C. \& Mention, A.- L. (2011.b). "Sustainable Finance: Collaborative Innovation Improving Confidence towards SRI Funds," Innovation for Financial Services, Innovation for Financial Services Summit, Luxembourg, Sep. 2011.

Vermeulen, C. \& Mention, A. L. (2011.c). 'Reporting Extra-Financial Performance in the Context of Socially Responsible Investments: Convergence between ESG and Intellectual Capital Approaches,' 7th EIASM Workshop on Visualizing Measuring and Managing Intangibles and intellectual Capital, Warsaw, Poland, Sep. 2011.

Wilsdon. T. \& Malcom, K. (2006). "Potential Cost Savings in a Fully Integrated European Investment Fund Market," CRA Project No D0-8482, pp.144, 2006. 


\section{Annexes}

\section{Annexe 1: Goal Modelling Constructs}

A role conveys the notion of an abstract actor, meaning that one or more concrete physical actors can assume the role. Actors in $i^{*}$ are strategic in that they seek relationships that will best suit their strategic interests. Each actor has its own strategic goals to pursue. Such goals are achieved through a network of intentional dependencies; that is, the actors depend on each other to achieve goals, perform tasks and furnish resources:

- Goal: A condition or state of affairs to be achieved. An actor can choose freely among different ways to achieve a goal.

- Task: A course of action to be carried out. It specifies a particular way of doing something, typically to achieve some goal.

- Resource: A physical or informational entity needed to achieve some goal or to perform some task.
- Soft goal: A goal without a clear-cut criterion for achievement, thus requiring further refinement and judgment. You might typically use this to represent quality goals.

Typical relationship types used to relate these elements are:

- Means-ends: means-ends link shows a particular way (typically a task) to achieve a goal.

- Decomposition: decomposition link Show how an intentional element (typically a task) is decomposed into subelements, which can include goals, tasks, resources and soft goals.

- Contribution: contribution link shows a contribution toward satisfying a soft goal, typically from a task or another soft goal.

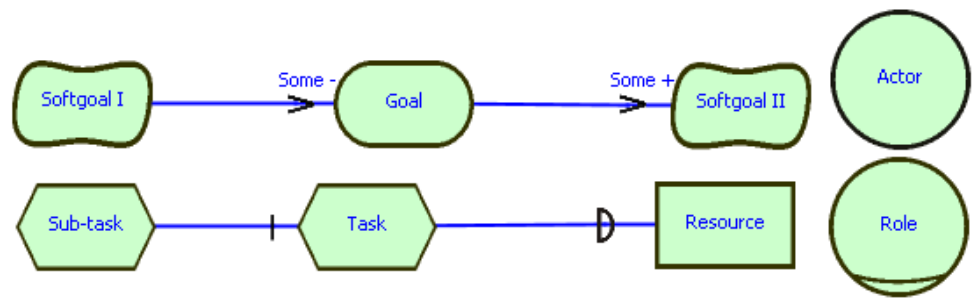

Figure 4: i* Constructs

The goal structures enable us to the space of alternatives available to each actor. The identified dependencies between actors offer opportunities but can also create vulnerabilities.

Using $i^{*}$ two types of models can be created:

- Strategic Dependency (SD) model, where each link between two actors indicates that one actor depends on the other for something in order that the former may attain some goal. The SD model is used to express the network of intentional, strategic relationships among actors.
- Strategic Rationale (SR) model is a graph that provides a representational structure for expressing the rationales behind dependencies. The actors with the SD model show their specific intentions.

\section{Annexe 2: Value Modelling Constructs}

We use the "Business Model Drawing Tool"xv as a simplification of the constructs of $\mathrm{e}^{3}$ value language (Gordijn \& al., 2006).

The main concepts used in value modeling are: 
- Actor: An actor is perceived by its environment as an independent economic (and often also legal) entity. An actor makes a profit or increases its utility. In a sound, sustainable, e-business model each actor should be capable of making a profit.
- Value object: Actors exchange value objects. A value object is a service, good, money, or experience, which is of economic value to at least one actor.

- Value exchange: A value exchange represents one or more potential, direct or indirect, trades of value objects.

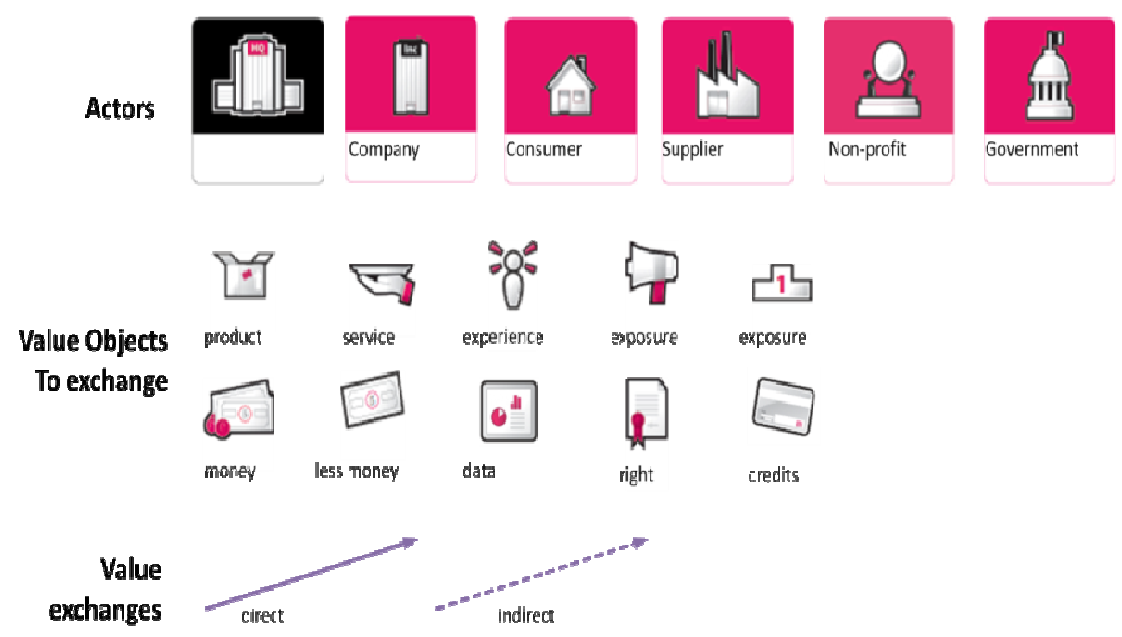

Figure 5: Value Network Constructs

\begin{abstract}
${ }^{\mathrm{i}}$ Asset under Management
ii Quoted in (Renneboog \& al., 2008)

iii For example, the "Autorité des Marchés Financiers" (AMF, Financial Markets Authority) is the regulator in France, the "Commission de Surveillance du Secteur Financier" (CSSF, Commission of Financial Sector Supervision) in Luxembourg, the "Financial Services Authority" (FSA) in United Kingdom, the "Swiss Financial Market Supervisory Authority" (FINMA) in Switzerland, etc.
\end{abstract}

iv Autorité des marchés financiers (AMF), Quebec, Canada. www.lautorite.qc.ca

v Examples listed in (Renneboog \& al., 2008)

vi In Australia: In a 2001 bill it is stated that all investment firms' product disclosure statements should include a description of "the extent to which labor standards or environmental, social or ethical considerations are taken into account". Since 2001, all listed companies on the Australian Stock Exchange are required to make an annual social responsibility report.

vii in Belgium: In 2001, Belgium passed the 'Vandebroucke' law, which requires pension funds to report the degree to which their investments take into account social, ethical and environmental aspects.

viii in France: In May 2001, the legislation "New Economic Regulations" came into force requiring listed companies to publish social and environmental information in their annual reports. Since February 2001 managers of the Employee Savings Plans are required to consider social, environmental or ethical considerations when buying and selling shares.

ix Vigeo Group is an European supplier of extra-financial analysis . It measures companies' performance in the field of Sustainable Development \& Social Responsibility to supply this information to Asset Managers. The Vigeo Group is also specialised in Social Responsibility audits for companies and organisations. Vigeo assesses the degree to which companies and public corporations take into account environmental, social, 
societal and corporate governance objectives, which constitute risk factors for them in the definition and implementation of their strategy and policies..

x ETHIBEL (www.ethibel.org) is an independent consultancy agency for SRI that advices banks and brokers offering ethical savings accounts and investment funds. ETHIBEL provides external verification to most Belgian investment funds with a social-ethical or ecological character.

xi Novethic (www.novethic.com), part of Caisse des Dépôts et Consignations, France, is a leading research centre in France on Corporate Social Responsibility (CSR) and Socially Responsible Investment (SRI) and a sustainable development media expert. The Novethic SRI Label has been launched by Novethic in 2009.

\author{
xii www.eurosif.org \\ xiii BELSIF in Belgium, \\ xiv www.belsif.be \\ xv www.boardofinnovation.com
}

